\title{
Parkinsonism and Haquapathy
}

\section{Faris Al Hajri*}

Researcher and Founder of Haqua Revitalize ${ }^{\circledR}$ Therapy (HART), Haqua Wellness, Blacksburg, Virginia

*Corresponding Author: Faris Al Hajri, Researcher and Founder of Haqua Revitalize® Therapy (HART), Haqua Wellness, Blacksburg, Virginia
Received: October 25, 2021

Published: December 30, 2021

(C) All rights are reserved by Faris Al Hajri.

\section{Abstract}

The purpose of this study is to seek an ultimate and most convenient solution with those who have been diagnosed with Parkinson's Disease through the root cause of the disease and seeking to revitalize the body back to its state of its physical health, rather than treating the disease through conventional medicine, which have been proven to just treat the symptoms, and thereafter leaving behind a series of drug-induced side effects. Human is irrevocably part of the entire nature, and therefore, seeking a permanent solution should only be conducted through nature. Whereas, nature is created, and not invented. Any interference to nature through invention results to detrimental side effects. However, the human body should strictly be adhered to the entire Cosmogenic Systems Laws of Nature (CSLN).

Keywords: Parkinsonism; Haquapathy; Nature

\section{Introduction}

Part 01- What is the concept of "Haquapathy"?

Haquapathy, otherwise coined Haquapathic Medicine (HAM), and trademarked as Haqua Revitalize ${ }^{\circledR}$ Therapy (HART); is a newly introduced system of natural therapy based on the concept that the body is created and not invented, and represents a system that required to be stimulated with its essential natural fuels to maintain its entire capacity towards functioning at its maximum impact, in the healing, and prevention from all dysfunctions that are usually the main cause towards diseases and all abnormal function of the system in any of the physical, emotional, mental, spiritual, and social aspects of health.

Haquapathy underlines revitalizing and energizing the body back to its state of entire PEMSS aspects of health and well-being (Physical, Emotional, Mental, Spiritual, and Social), through the implementation of Haqua Revitalize ${ }^{\circledR}$ Therapeutic Modalities (HRTM) towards individuals' inherent self-protection, self-maintenance process and self-healing.

\section{Part 02- Understanding Parkinson's disease}

According to The Parkinson's Foundation, a US nonprofit organization, Parkinson's disease (PD) has been defined as a neurodegenerative disorder that affects predominately dopamine-producing ("dopaminergic") neurons in a specific area of the brain called substantia nigra. In addition to movement-related ("motor") symptoms, Parkinson's symptoms may be unrelated to movement ("nonmotor"). People with PD are often more impacted by their nonmotor symptoms than motor symptoms. Examples of non-motor symptoms include apathy, depression, constipation, sleep behavior disorders, loss of sense of smell and cognitive impairment [1].

The American Parkinson Disease Association has defined Parkinson's disease as a type of movement disorder that can affect the ability to perform common, daily activities. It is a chronic and progressive disease, meaning that the symptoms become worse over time [2].

In an article published by the American Parkinson Disease Association, it stated that certain environmental factors, such as signifi- 
cant exposure to pesticides or certain heavy metals and repeated head injuries, can increase risk of Parkinson's. There are other things that put an individual at higher risk for developing Parkinson's. The main risk factor is age, because Parkinson's disease is most commonly found in adults over the age of 50 (although diagnoses can occur in much younger people). Men also have a higher risk of Parkinson's disease than women [3].

\section{Drug-induced Parkinson's disease}

In article published by MedlinePlus, a U.S. National Library of Medicine, the world's largest biomedical library, stated certain drugs could cause tremor. Drug-induced tremor is a simple nervous system and muscle response to certain medicines. Drugs that can cause tremor include the following:

- $\quad$ Cancer medicines such as thalidomide and cytarabine

- Seizure medicines such as valproic acid (Depakote) and sodium valproate (Depakene)

- Asthma medicines such as theophylline and albuterol

- Immune suppressing medicines such as cyclosporine and tacrolimus

- Mood stabilizers such as lithium carbonate

- $\quad$ Stimulants such as caffeine and amphetamines

- Antidepressant drugs such as selective serotonin reuptake inhibitors (SSRIs) and tricyclics

- Heart medicines such as amiodarone, procainamide, and others

- Certain antibiotics

- Certain antivirals, such as acyclovir and vidarabine

- Alcohol

- $\quad$ Nicotine

- $\quad$ Certain high blood pressure drugs

- $\quad$ Epinephrine and norepinephrine

- Weight loss medicine (tiratricol)

- $\quad$ Too much thyroid medicine (levothyroxine)

- Tetrabenazine, a medicine to treat excessive movement disorder [4].

Healthline Media, an American website and provider of health information, published a list of drug-induced parkinsonism. It stated that drug-induced parkinsonism is caused by medications that reduce dopamine levels in the brain. Dopamine is a neurotransmit- ter that works to control bodily movements. Medications that bind to and block dopamine receptors are called dopamine antagonists. These medications aren't used to treat Parkinson's disease. Rather, they're used to treat other conditions that might seriously impact your quality of life.

Some medications that cause drug-induced parkinsonism include:

- Antipsychotics

Antipsychotic medications are used to treat several disorders, including:

- Schizophrenia

- Bipolar disorder

- Alzheimer's disease

- Tourette syndrome

- Anxiety disorders

- Depression

Some antipsychotics that might cause parkinsonism include:

- Fluphenazine

- Chlorpromazine

- Promazine

- $\quad$ Pimozide

- Haloperidol

- $\quad$ Perphenazine

- Anti-nausea medication

Some medications used to treat motion sickness, nausea, and vertigo block dopamine receptors and can cause parkinsonism. They include antihistamines such as:

- Hydroxyzine

- $\quad$ Promethazine

- Gastrointestinal prokinetics

Gastric motility disorders are digestive conditions that occur when the nerves or muscles in the gut don't function in a coordinated manner. Some medications used to treat this condition can cause parkinsonism as a side effect. They include:

- Metoclopramide

- Prochlorperazine

- Levosulpiride 
Calcium channel blockers are used to treat cardiovascular conditions such as high blood pressure and chest pain. They're also used to treat neurological disorders. In some instances, calcium channel blockers may cause movement disorders and parkinsonism.

Calcium channel blockers have also been shown in studies Trusted Source to reduce the risk of getting first-time Parkinson's disease.

One example of a calcium channel blocker is diltiazem.

\section{Anticonvulsant medication}

Valproate, an antiseizure drug used to treat epileptic seizures and convulsions is the type of medication in this class most likely to cause parkinsonism.

\section{Antidepressants}

- $\quad$ Serotonin reuptake inhibitors (SSRIs) are widely used as antidepressants and mood stabilizers. These medications may cause or worsen parkinsonism in some instances.

- Serotonin-norepinephrine reuptake inhibitors (SNRIs), another form of antidepressant, may also have this effect. SNRIs are used to treat major depressive disorders, ADHD, fibromyalgia, and other conditions.

- Extensive or long-term exposure to environmental toxins is another potential cause of parkinsonism. It's thought that these chemicals cause oxidative stress or mitochondrial dysfunction, which can lead to movement disorders.

- $\quad$ Some toxins, including certain pesticides, may also pose a risk for Parkinson's disease.

Pesticides to avoid include:

- Paraquat

- $\quad$ Rotenone

Parkinson's disease is a chronic, neurodegenerative brain disorder. In addition to problems with movement, Parkinson's disease causes non-motor symptoms that aren't caused by drug-induced parkinsonism. They include:

- Depression

- $\quad$ Problems with sleep

- Constipation

- $\quad$ Anosmia (loss of smell) [5].
In an article published in the American Parkinson Disease Association (APDA), Posted on September 29, 2020 by Dr. Rebecca Gilbert, APDA Vice President and Chief Scientific Officer, she stated the medications that can cause tremor include, but are not limited to, lithium, valproic acid, amiodarone, beta-adrenergic agonists, and selective serotonin reuptake inhibitors (SSRIs).

Certain prescription medications can block the dopamine receptor in the brain and cause symptoms that resemble PD, referred to as parkinsonism.

- $\quad$ Anyone who develops motor symptoms of PD should have their medications reviewed.

- Medications that block the dopamine receptor are particularly harmful to people with PD who already have a depletion of dopamine in the brain.

- Many other medications that do not block the dopamine receptor can cause postural and action tremors [6].

\section{Haqua revitalize ${ }^{\circledR}$ therapeutic effects (hartef) to Parkinson's} disease- scientific hypothesis

Hydrate is defined as to make the body absorbing water, whereas Haquate is a new scientific terminology we coined it, as to make the body absorbing water, oxygen, hydrogen, and energy. These natural elements, termed as the Four Essential Elements of Life, or simply the FEELs, are exclusively found in water at specific temperature, at different amount of consumption, with a specific daily program, for consumption use in adults and that in children, which we coined it the Therapeutic Methods of Haqua Gulping, or simply the TMHG, and other modalities. We specifically preferred to use the word gulping than drinking, since the water temperature is hot enough a person can tolerate to fill-up the mouth at every gulping, without causing any burn, or harm from the heat related to the water.

In our studies, compiled from various studies, we found Haqua is the exclusive source of the two main factors: -

- The source of creation and growth of every human without any single distinction. Without Haqua, no human being would ever exist in the universe. The moment fetal growth begins, a pure liquid, known as amniotic fluid, fills the amniotic sac. The temperature rises to one degree Celsius above the mother's normal body temperature. This liquid is comprised of $99 \%$

Citation: Faris Al Hajri. "Parkinsonism and Haquapathy". Acta Scientific Neurology 5.1 (2022): 16-29. 
water [7], and its temperature stand steadily at 37.6 degree Celsius (99.7-degree Fahrenheit) [8] is basically Haqua, which is 1 degree Celsius higher than the mother's normal body temperature, in which the fetal development takes place to secure absorption of the FEELs, namely: water, oxygen, hydrogen, and energy.

- The source of life to every living organism, resulted from the hydrologic cycle.

Our extensive personal studies we conducted for the past fourteen years since our first discovery of Haqua Revitalize ${ }^{\circledR}$ Therapy (HART) since 2007, we found it being the fundamental core of the most vital role in every single biological, genetic, psychological aspects of the human life, including most of all basics of science, precisely; physics, chemistry, and even biology.

The concept of the four essential elements of life (feels) with regards to the five aspects of health (FAH)

Each of the FEELs (Four Essential Elements of Life) found in water at higher temperature represents one of the most holistic approaches known to science, represented as follows: -

- Water therapy, otherwise known as Aquatic Therapy, or Hydrotherapy.

- Oxygen therapy, otherwise known as hyperbaric therapy.

- Hydrogen therapy

- $\quad$ Energy therapy

Parting each of these therapies may be the clue to the limited success, mostly in the academic workforce and scientific societies, and has resulted to string of controversies and obviously rejected by both the academic workforce and the scientific societies to be considered as pseudoscience.

Haqua Revitalize ${ }^{\circledR}$ Therapy (HART), otherwise coined as Haquapathic Medicine (HAM), or simply Haquapathy, exclusively merges all these four therapeutic approaches, through a single source; Haqua, and Haquapathy, which initially were derived from its generic name as hot water, and hot water therapy respectively.

The four essential elements of life (feels) from haquapathy scientific rational

Haqua Revitalize ${ }^{\circledR}$ Therapy (HART), otherwise coined as Haquapathic Medicine (HAM), or simply Haquapathy, exclusively merges all these four therapeutic approaches, through a single source; Haqua, and Haquapathy, which initially were derived from its generic name as hot water, and hot water therapy respectively.

The accessibility of all the FEELs, namely water; oxygen, hydrogen, and energy, or simply WOHE; has been scientifically substantiated by series of scientific methodologies we collected from various sources, each has been emphasized in various Parts of this book, and here we hereby assemble and shorten them as follows.

\section{Part 01- The cosmic cycle}

The moment fetal growth begins, a pure liquid, known as amniotic fluid, fills the amniotic sac. The temperature rises to one degree Celsius above the mother's normal body temperature. This liquid is comprised of $99 \%$ water7, and at 37.6 degree Celsius (99.7-degree Fahrenheit) 8 is basically Haqua. This pure Haqua was naturally formed as well, without any foreign interference. So far, there is no scientific discovery happened yet to increase or reduce the temperature and volume of this liquid. During this process, the baby inside the womb of the mother is continuously injected with essential amount of water, oxygen, hydrogen, and energy, we coined, the FEELs (Four Essential Elements of Life). At the time the baby is born, his or her body is fully contained of remarkable volumes of each of these FEELs. They start to get gradually depleted after the child's birth. The exclusive approach to maintain them, is precisely by implementing Haqua Revitalize ${ }^{\circledR}$ Therapy (HART) to the newly born baby, and all throughout the lifespan, in accordance with our strict recommendation, by volume and temperature, and other modalities, emphasized in this book. This process has been coined the CSLN (Cosmogenic Systems Laws of Nature), which no science can every alleviate or manipulate it. Making the exclusive difference between inventing and creating. Anything that is invented, would certainly pose threat and harm than do good, to anything that is created, once both come into contact.

Invention can only occur by human's scientific achievements. Whereas creation should only be studied and strictly adhering to its biological function. For this reason, diseases, anxieties, stress, etc; are only defined as body's dysfunction. We are obliged to abide with finding the deep root causes, by understanding that the full function and performance of a living creature, fully relies on the provision of its essential natural fuels, precisely, the FEELs. Without them, the entire biological system will gradually collapse, physically, emotionally, mentally, spiritually, and even socially. 
Since amniotic fluid, or amnii, is the exclusive source of every human's creation and development; therefore, the FEELs are the exclusive means to maintain the full potential of the entire PEMSS (Physical, Emotional, Mental, Spiritual) Aspects of health.

\section{Part 02- The hydrogen cycle}

Plants are able to use infrared light from the sun to break down water $\mathrm{H}_{2} \mathrm{O}$ into hydrogen and oxygen. The plants exhale oxygen into the atmosphere and add the hydrogen to carbon in order to make carbohydrates, proteins and lipids. Plants create carbohydrates, proteins and lipids by attaching hydrogen to carbon atoms like hats on a hat-rack. The 'burning of the hydrogen' is a secret of life [9].

The main ingredients for plant growth are water, air, and energy. A plant can be up to $95 \%$ water [10].

\section{Part 03- The hydrologic cycle}

Humans always feel more refreshed after being near water. This is partly due to the "Hydrologic Cycle" in which the sun's energy on the surface of the water causes the water molecules containing hydrogen and oxygen to become active.

In a process known as the hydrologic cycle, or the water cycle. Let us take a quick review on this issue from the National Oceanic and Atmospheric Administration. The hydrologic cycle involves the continuous circulation of water in the Earth-Atmosphere system. At its core, the water cycle is the motion of the water from the ground to the atmosphere and back again. Of the many processes involved in the hydrologic cycle, the most important are evaporation, transpiration, condensation, precipitation, and runoff.

Evaporation is the change of state in a substance from a liquid to a gas. In meteorology, the substance we are concerned about the most is water. For evaporation to take place, energy is required. The energy can come from any source: the sun, the atmosphere, the earth, or objects on the earth such as humans [11].

The interesting fact, as Haqua is not only the exclusive the source of creation of every single human being on planet, but also, it the exclusive source of the hydrologic cycle, known as the water cycle, which usually generates rain, thunderstorm, cyclones, hurricanes, etc. Without sunlight, water in oceans, and lakes which in return cause its surface to warm up and turn to become "Haqua", there would never be rain, nor would the water cycle ever occur.
Thus, we conclude that Haqua, not only being the source of creation and growth of every human being on this planet, in addition, it is also the only source of life on this planet as well. Without water on the surface of oceans, lakes, and rivers being heated by the sun, water would ever remain stagnant, and the hydrologic cycle would never take place, and every living organism on earth would immediately extinct.

\section{Part 04- Calories burning}

Calorie is defined as the amount of heat required to raise the temperature of one gram of water from 14.5 degrees Celsius to 15.5 degrees Celsius." Heat is also sometimes measured in "British thermal units" or Btu [12].

Haqua Revitalize ${ }^{\circledR}$ Therapy (HART) can be taken into significance the hypothesis for burning the calories faster and better, heat transfer and thermogenesis, since the Haqua Revitalize ${ }^{\circledR}$ Therapy (HART) is the only method where calories could be naturally and effortlessly burned and exclusively, by hydration. The presence of the Four Essential Elements of Life (FEELs) are therefore found to play a vital role on the issue of calories burning; specifically two of the Four Essential Elements of Life (FEELs); namely "Water" and "Heat", whereas heat is the main source of energy.

Here is what happens when the body burns out calories, in relation to Haqua Revitalize ${ }^{\circledR}$ Therapy (HART). Whenever you perform body workouts, exercises, or any physical activities, as our bodies contain more than $75 \%$ water; this water is thereby heated up through the kinetic energy by the dynamic movement of the body, and the muscles would be heated up, at the time of performing the body exercises, which in return would lead to thermogenesis as the internal temperature of the body raises up.

With everyone gram of water in our body being heated by just one degree Celsius that is what is considered a calorie. But why the discovery of calorie was specifically linked with the temperature of water starting at 14.5 degree Celsius, and not below that temperature?

Well, here in our hypothesis is that water below 14.5 degree Celsius will be below room temperature. At the said degree, the water is considered warm.

In adopting the HART (Haqua Diet Therapy), It is being observed that a Haqua and calorie are interrelated. In simple words, 
scientific calorie data is co-related with water amount and heat consistency.

\section{Part 05- Metabolism}

- Food Metabolism phenomenon that is known as to be one to convert all chemical and physical processes into useable energy. In human beings an effective series of event occur that make human body capable of utilizing food. The energy that is derived from the food metabolism provides power to think and grow. In digestive system, several enzymes break the complex protein, fats and carbohydrates of food eaten into simple amino-acids, fatty acids, and glucose. Whenever body needs these energy components, these three simple energy sources are utilized.

- Energy sources such as amino acids, fatty acids, and glucose absorbed in the blood that enhance enzymes action and metabolize the chemical and physical reactions. During this phenomenon, the energy components produced stored in human body tissues such as in muscles, liver, etc.

- In accordance to review article of Mayo Clinic, it is demonstrated that how metabolism reduces the calories. What is the reason behind burning more calories in relation with slow metabolism? In accordance to their scientific definition, it is regarded as the phenomenon in which whatever eat or drink is converted into energy stored in body tissues. Metabolism is a complex phenomenon in which energy calories are combined with oxygen that make capable body to function. This energy is utilized even if human body is at rest, for example for functions such as blood circulation, hormonal regulation, breathing and repairing cells. Basal Metabolic rate is defined as body uses how many calories for performing basic human body functions [13].

- In accordance to recent study on metabolism and cancer, Albert von Szent-Gyorgyi noted that all the energy which drives life is generated in the sun by atomic reactions and some of this energy, commonly known as "sunshine", is captured by the photosynthetic apparatus of plants - a process where plants absorb sunlight and turn that energy into food. Through this reaction, sunshine is exchanged for thermodynamic potential, that of $\mathrm{H}$ and $\mathrm{O}$, and henceforth, the sole source of the energy of life must be this thermodynamic potential. To support life, this potential is released by reversing the reaction which produced the potential: the splitting of water and bringing $\mathrm{H}$ and 0 together to form water again, in other words: oxidizing the hydrogen. The big energy gap between $\mathrm{H}$ and $\mathrm{O}$ can be bridged by performing the oxidation of $\mathrm{H}$ piecemeal in reversible steps. This oxidation of the hydrogen is the core of the metabolism [14].

- Biochemist Albert Szent-Györgyi discovered that hydrogen, rather than oxygen, was the fuel of life. Mankind needs oxygen to exist, but oxygen's counterpart (hydrogen) is the real fuel. Oxygen burns hydrogen, releasing the energy (in the form of ATP) that runs our bodies. Water supplies both the fuel (hydrogen) and the fire (oxygen), but hydrogen is often the limiting factor [15].

- Let us take a deep look into the effect of heat in regards to the metabolic system where foods are being broken down by enzymes which are known to be the proteins that break down foods into energy we need. It is scientifically defined that heat is produced in the body by the continuous metabolism of nutrients which provides energy for the systems of the body $[16,17]$.

For the secure and proper food nutrition importance on this subject goes to increase by the advancement in scientific findings. For burning fat and enhancement of food metabolism by physical exercise along with low calories consumption occur. As, it is much more difficult for some people to maintain or follow the strict diet plan as their body is adhered to high calorie food. Commonly all humans and athletes suffering from health issues related to bone such as, osteoarthritis, rheumatisms, arthritis, and other complex issues struggle to recover at later stage in life by taking exercises. Human Body's (FEELs) Four Essential Elements of Life get depleted and then human start struggling for healthcare.

For the achievement of healthy lifestyle, there is a primary key known as Haqua Revitalize ${ }^{\circledR}$ Therapy (HART). Along with that appropriate exercise schedule and proper diet plan are needed for maintaining a healthy and good lifestyle.

Haqua Revitalize ${ }^{\circledR}$ Therapy (HART) mysteries are hidden, and scientific findings reveal that exercise and food nutrition controversies would be removed. Haqua Diet Therapy (HDT) is one of the most important modalities of Haqua Revitalize ${ }^{\circledR}$ Therapy (HART) for body fitness and weight loss. This therapy reduces the food intake up to $90 \%$ and allows human body to boost up natural cleanliness through 'Haquation'. By this scientific strategy, daily food in- 
take reduces and ultimately the metabolic rate lowers. Hypothesis behind this scientific plan is that 'Haquation' is the phenomenon by which food metabolism gets lower as Haqua transfer body energy.

Dehydration, often caused by excessive exposure to sunlight or physical activity, results in the loss of body energy. This leads to the inability of the body to perform proper metabolism due to a lack of water. It has been medically proven that a mere $2 \%$ drop in our body's water supply can trigger signs of dehydration. Just a 5\% drop in body fluids will cause a $25 \%$ to $30 \%$ loss of energy in the average person, and a $15 \%$ drop in body fluids causes death. It is estimated that over $80 \%$ of our population suffers energy loss due to minor dehydration [18].

Adenosine Triphosphate (ATP) (an energy-bearing molecule found in all living cells) is obtained from the breakdown of foods. The energy in ATP can be released as heat or can be used in the cell as a power source to drive various types of chemical and mechanical activities.

The hydrolysis (a decomposition process that occurs when a substance reacts with water) of ATP is accelerated by an enzyme called adenosine triphosphatase [19].

Heat is produced in the body by the continuous metabolism of nutrients which provide energy for the systems of the body. The human body must maintain a consistent internal temperature to maintain healthy bodily functions [20].

Both heat, and hydrolysis in ATP is effortlessly provided by Haqua Revitalize ${ }^{\circledR}$ Therapy (HART), which in turn enriches its acceleration.

Cold Water slows down the metabolism, solidifies the fat deposits inside our bodies, mostly our intestine, stomach and blood vessels, and in return it causes hypertension due to lack circulation of blood, including many other adverse health effects.

It is recommended, therefore, that the daily volume of food eaten is lowered upon implementing the Therapeutic Methods of Haqua Gulping (TMHG) and the Haqua Diet Therapy (HDT).

\section{Part 06- The PH value of water}

In an article published by Jim Clark, a retired researcher from Truro School in Cornwall, England, supported by UC Davis, the California State University, said that the formation of hydrogen ions (hydroxonium ions) and hydroxide ions from water is an endothermic process. If the $\mathrm{pH}$ falls as temperature increases, this does not mean that water becomes more acidic at higher temperatures. A solution is acidic if there is an excess of hydrogen ions over hydroxide ions (i.e., $\mathrm{pH}<\mathrm{pOH}$ ). In the case of pure water, there are always the same concentration of hydrogen ions and hydroxide ions and hence, the water is still neutral $(\mathrm{pH}=\mathrm{pOH})$ - even if its $\mathrm{pH}$ changes. At $100^{\circ} \mathrm{C}$, the $\mathrm{pH}$ of pure water is 6.14 , which is "neutral" on the $\mathrm{pH}$ scale at this higher temperature [21].

$\mathrm{pH}$ of pure water with temperature

\begin{tabular}{|l|l|}
\hline $\mathbf{T}\left({ }^{\circ} \mathbf{C}\right)$ & $\mathbf{p H}$ \\
\hline 0 & 7.47 \\
\hline 10 & 7.27 \\
\hline 20 & 7.08 \\
\hline 25 & 7.00 \\
\hline 30 & 6.92 \\
\hline 40 & 6.77 \\
\hline 50 & 6.63 \\
\hline 100 & 6.14 \\
\hline
\end{tabular}

Table a

All these scientific facts are strong enough to substantiate our hypotheses whereby implementing Haqua Revitalize ${ }^{\circledR}$ Therapy (HART), Haquapathic Medicine (HAM), or simply Haquapathy; would be the exclusive means to keep the body Haquated, rather than just hydrated, altogether at once with all the FEELs (Four Essential Elements of Life), namely water, oxygen, hydrogen, and energy; or simply WOHE.

The effects of the four essential elements of life (feels) to Parkinson's disease - scientific facts

\section{Part 01- Water W.E.T. Parkinson}

Marla Cone, an Environmental Health News from Scientific American, published an article on August 5, 2009 where she stated that over the past few years, a growing body of evidence has led many experts to suspect that pesticides can attack developing brains, perhaps in the womb or infancy, leading to neurological diseases later in life. Many insecticides widely used on farms are potent neurotoxins, and lab animals exposed to mixes of them develop Parkinson's symptoms. 
In addition, several previous studies of farmers and rural residents have reported a link. The new study of more than 700 people in California's Central Valley found that those who likely consumed contaminated private well water had a higher rate of Parkinson's [22].

Two researchers from the Department of Neurology, Jichi Medical School Omiya Medical Center, Japan (Ueki A., et al. 2004) published in the Journal of Neurology, and the National Library of Medicine, found that gastrointestinal dysfunction, especially constipation, is one of the major problems in the daily life of patients with Parkinson's disease (PD). About 60 to $80 \%$ of PD patients suffer from constipation. Intake of water was significantly decreased in PD patients from early life and associated with their constipation. Interestingly, PD patients tended not to feel thirsty and thus they had no desire to drink water throughout their life. Furthermore, the amount of water intake correlated inversely with the severity of constipation and the depletion of water intake preceded constipation in most cases [23].

Lindsay Adler, a Neurology Solutions Contributing Writer in Neurology Solutions (Adler L. 2017), in her published article stated that dehydration in Parkinson's disease (PD) is a major concern because the risks associated with becoming dehydrated can significantly worsen already compromised neurological function. Complicating matters even more, it is very easy to misread symptoms of dehydration for symptoms common to PD. The body is made up of over $70 \%$ water, and it moves throughout the membranes from the blood to the lymph system, to the organs, and to the brain. It's needed to transport vital nutrients like minerals, vitamins and amino acids to cells and extract waste from every cell. Water also affects the efficiency of the nervous system and plays a role in cerebral blood flow [24].

\section{Part 02- 0xygen W.E.T. Parkinson}

A study conducted by a group of researchers from the Department of Neurology and Centre for Clinical Neuroscience, Daping Hospital Third Military Medical University, Chongqing, China (Sun H., et al. 2019); conducted to a group of male patients with obstructive sleep apnea syndrome (OSAS), found that chronic intermittent hypoxia (a condition in which there is not enough oxygen available to the blood and body) can increase the $\alpha$-synuclein levels, which may contribute to the pathogenesis of Parkinson's disease [25].

\section{Part 03- Hydrogen W.E.T. Parkinson}

In an article by Patrick Flanagan MD, an American research scientist, published by Vital Vibe Source, taken from a series of research articles, where it emphasized that the carbon cycle could actually be renamed the 'hydrogen cycle'. Several patents have been issued lately that take advantage of the fact that plants are able to use infrared light from the sun to break down water $\mathrm{H}_{2} 0$ into hydrogen and oxygen. The plants exhale oxygen into the atmosphere and add the hydrogen to carbon in order to make carbohydrates, proteins and lipids. Plants create carbohydrates, proteins and lipids by attaching hydrogen to carbon atoms like hats on a hat-rack. Carbohydrates contain an equal amount of carbon, hydrogen and oxygen. We can say that all the foods that nourish us are primarily sources of hydrogen. We can see that the life cycle is really a hydrogen cycle. The 'burning of the hydrogen' is a secret of life [9].

In an article published by Jim Clark, a retired researcher from Truro School in Cornwall, England, supported by UC Davis, the California State University, said that the formation of hydrogen ions (hydroxonium ions) and hydroxide ions from water is an endothermic process. If the $\mathrm{pH}$ falls as temperature increases, this does not mean that water becomes more acidic at higher temperatures. A solution is acidic if there is an excess of hydrogen ions over hydroxide ions (i.e., $\mathrm{pH}<\mathrm{pOH}$ ). In the case of pure water, there are always the same concentration of hydrogen ions and hydroxide ions and hence, the water is still neutral $(\mathrm{pH}=\mathrm{pOH})$ - even if its $\mathrm{pH}$ changes. At $100^{\circ} \mathrm{C}$, the $\mathrm{pH}$ of pure water is 6.14 , which is "neutral" on the $\mathrm{pH}$ scale at this higher temperature [21].

In an article published by an industry-leading laboratory design and equipment mentioned that $\mathrm{pH}$ decreases with increase in temperature. But this does not mean that water becomes more acidic at higher temperatures. A solution is considered as acidic if there is an excess of hydrogen ions over hydroxide ions. In the case of pure water, there are always the same concentration of hydrogen ions and hydroxide ions and hence, the water is still neutral (even if its $\mathrm{pH}$ changes). At $100^{\circ} \mathrm{C}$, a pH value of 6.14 is the New neutral point on the pH scale at this higher temperature [26].

A researcher from the Department of Neurology and Psychiatry, Saint Louis University School of Medicine, Saint Louis, Missouri, US, (Brenner S. 2013), found that melanin, a hybrid electronic/ionic conductor may have the potential to split the water molecule into molecular hydrogen and molecular oxygen. Molecular hydrogen is 
an antioxidant and may be instrumental in preventing the excessive oxidation leading to Parkinson's disease. Melanin, located in the Substantia Nigra, deteriorates in Parkinson's disease so may be related to the development and progression of the disease, since molecular hydrogen would no longer be generated as it deteriorates.

Environmental toxins, thought to be related to development of Parkinson's disease, may cause deterioration of intrinsic melanin, since it is a chelator which would collect such environmental contaminants, but its function of splitting the water molecule into molecular hydrogen and oxygen could be effected as a consequence. Restoring melanin function or providing supplemental molecular hydrogen might be potential treatments for Parkinson's disease [27].

Another study from by group of researchers from Kyushu University, Fukuoka, Japan (Yoshii Y., et al. 2017), found that molecular hydrogen $\left(\mathrm{H}_{2}\right)$, as a new medical gas, has protective effects in neurological disorders including Parkinson's disease (PD) [28].

A study conducted by a group of researchers from Laboratory of Pathophysiology, Graduate School of Pharmaceutical Sciences, Kyushu University, Fukuoka, Japan (Fujita K., et al. 2009) found that drinking $\mathrm{H}_{2}$-containing water may be useful in daily life to prevent or minimize the risk of lifestyle-related oxidative stress and neurodegeneration. Chronic oxidative stress causes neurodegenerative diseases such as Parkinson's disease (PD) [29].

\section{Part 04- Energy W.E.T. Parkinson}

In this article published by the American Parkinson Disease Association (APDA) stated that fatigue is a common but underrecognized problem for people with Parkinson's disease (PD). Fatigue can be defined as an unpleasant sensation of lacking energy, making the performance of routine activities, physical or mental, a strain. People with PD may experience physical fatigue, mental fatigue, or both. For many people, medications taken for the motor symptoms of Parkinson's disease can worsen fatigue. Being in poor physical condition can worsen fatigue and for some people, exercise can improve fatigue [30].

\section{The purification process of water}

The quality of the water used for gulping should be safe drinking-water, as defined by the guidelines for Drinking-water Quality comprising health-based targets established by a competent health authority; adequate and properly managed systems (adequate infrastructure, proper monitoring and effective planning and management); and a system of independent surveillance.

Purification of water from pathogenic substances, bacteria etc. is done by means of boiling water, one of the easiest purification techniques for water purification.

Water purification is the process of removing undesirable chemicals, biological contaminants, suspended solids and gases from contaminated water that may be unsafe for drinking, bathing or washing.

The purification process of water may reduce the concentration of particulate matter including suspended particles, parasites, bacteria, algae, viruses, fungi; and a range of dissolved and particulate material derived from the surfaces that water may have made contact with after falling as rain.

Boiling water kills or inactivates viruses, bacteria, protozoa and other pathogens by using heat to damage structural components and disrupt essential life processes.

For pasteurization to be effective, water or food must be heated to at least the pasteurization temperature for the organisms of concern and held at that temperature for a prescribed interval [31].

Boiling can be used as a method of water disinfection. Bringing water to the boil is effective in killing or inactivating most bacteria, viruses and pathogens. Boiling is the most certain way of killing nearly all microorganisms. According to the Wilderness Medical Society, water temperatures above $160^{\circ} \mathrm{F}\left(70^{\circ} \mathrm{C}\right)$ kill all pathogens within 30 minutes and above $185^{\circ} \mathrm{F}\left(85^{\circ} \mathrm{C}\right)$ within a few minutes. So in the time it takes for the water to reach the boiling point $\left(212^{\circ} \mathrm{F}\right.$ or $\left.100^{\circ} \mathrm{C}\right)$ from $160^{\circ} \mathrm{F}\left(70^{\circ} \mathrm{C}\right)$, all pathogens will be killed, even at high altitude. In places where the available water supply is contaminated with disease-causing bacteria, boiling water and allowing it to cool before gulping it is practiced as a valuable health measure [32].

In an article published by the World Health organization, accentuated that enteric bacteria, protozoa and viruses in liquids are sensitive to inactivation at temperatures below $100^{\circ} \mathrm{C}$. Thermal inactivation has been examined in water, sewage, milk and other liquids at temperatures close to those used for pasteurization (e.g. 
$63^{\circ} \mathrm{C}$ for 30 minutes, $72^{\circ} \mathrm{C}$ for 15 seconds) and in hot water (about $60^{\circ} \mathrm{C}$ ). Only a few studies have examined thermal inactivation in liquids at temperatures approaching $100^{\circ} \mathrm{C}$. The article concluded that based on these results, it is considered that the process of heating water to a rolling boil, as recommended in the WHO Guidelines for Drinking-water Quality (WHO, 2011), is sufficient to inactivate pathogenic bacteria, viruses and protozoa. After the water has reached a rolling boil, it should be removed from the heat, allowed to cool naturally, without the addition of ice, and protected from post-treatment recontamination during storage. If turbid water needs to be clarified for aesthetic reasons, this should be done before boiling [33].

Haqua revitalize therapeutic modalities (HRTM) with regards to Parkinson's disease

Part 01- Therapeutic methods of haqua gulping-TMHG

[glass size $500 \mathrm{ml}(17 \mathrm{oz})$ ]

The TMHG is categorized into a series of subsections, depending to a person's suitable timings. Here, we have picked up the most common therapeutic method, coined the HCGM (Haqua Common Gulping Method), as follows:

- $\quad$ One glass upon waking and on a 'clean' mouth* - at a standing position. *

- One glass between 7:00-10:00 a.m.

- One glass 15-30 minutes before lunch. **

- $\quad$ One glass between 2:00-4:00 p.m.

- $\quad$ One glass in the evening, 15-30 minutes before dinner. **

- $\quad$ One glass an hour before sleep. **

Part 02- Haqua gulping for urgent cases (HGU)

[glass size $500 \mathrm{ml}(17 \mathrm{oz})$ ]

(This method is highly recommended for use during urgent and emergency needs, such as, but not limited to, vomiting, headache, cold, flu, cough, High Blood Pressure, High Blood Sugar, Food Poisoning, Lethargy, etc.)

- $\quad$ Gulp 2 liters (68 oz) of Haqua spread in a span of 2 hours, by gulping a glass of $500 \mathrm{ml}(17 \mathrm{oz})$ glass, mug, or tumbler of Haqua at 30 minutes intervals

- $\quad$ Continue the gulping method for the remainder of the day as recommended.
Remarks

- *Haqua should be taken before brushing teeth, mouthwash, or eating anything.

- $\quad$ ** Should be given high consideration. Haqua will detoxify the body, removing toxins which are in form of gases (Carbon Dioxide- $\mathrm{CO}_{2}$, Hydrogen Sulfide- $\mathrm{H}_{2} \mathrm{~S}$, Nitrogen-N, and Methane$\mathrm{CH}_{4}$ ).

- The daily recommended consumption of Haqua is a minimum of 3 liters (101 oz) and maximum of 4 liters (135 oz) under normal condition. The daily intake quantity may exceed, depending on certain conditions; such as but not limited to intensive physical activities, athletic and sports activities, extreme hot or cold weather conditions, conducting public speeches for more than an hour, etc.

- $\quad$ The water volume taken should not exceed $500 \mathrm{ml}(17 \mathrm{oz})$ at one time, and a maximum of 1 liter in the span of an hour.

- Shall abide with the recommended temperature of Haqua, fixed at around $50^{\circ} \mathrm{C}\left(122^{\circ} \mathrm{F}\right)$, a little bit less than the temperature of hot tea or hot coffee.

- There are three ways to ingest water or another liquid by the mouth: drinking, sipping, or gulping. This therapy requires the subject to gulp Haqua (hot water), instead of drinking or sipping it.

- A glass of Haqua should be slowly gulped in mouthfuls without stopping. The intervals between gulps should be around 5-10 seconds.

- A whole tumbler of size of $500 \mathrm{ml}$ (17 oz) is highly recommended every 2-3 hours.

- Good quality tumblers are usually made up of high insulated materials that may maintain the heat between 6-12 hours.

- It takes around 1-2 minutes to gulp a whole $500 \mathrm{ml}(17 \mathrm{Oz})$ glass, tumbler, or mug of Haqua taken between 9-15 gulps at temperature around $50^{\circ} \mathrm{C}\left(122^{\circ} \mathrm{F}\right)$.

- Do not exceed more than a 3 hour-interval, except in urgent and exceptional cases.

- $\quad$ Do not gulp more than 1liter (34 oz) Haqua within 1 hour.

- It is strongly recommended that mixing your Haqua with any additives is to be avoided. Any change of water's temperature, or addition of additives, immediately alters its molecular state, and it can even become toxic. 
- Because the body will rid itself of toxins, there may be a few unpleasant side-effects. This, however, is a natural result and a healthy response to Haqua's cleansing work. The detoxification process includes excreting metabolic wastes, accumulated toxins, harmful bacteria and excess fat deposits (lipids).

- $\quad$ There may be some irregular stomach discharge, frequent urination and sweating. This symptom usually lasts for a week or two (more or less) before the body gets revitalized back to its normal condition.

- $\quad$ Some vomiting is possible and may continue for 1-2 times while the body detoxes.

- A specific Therapeutic Methods of Haqua Gulping (TMHG) for children and babies has been formulated, in terms of temperature, quantity and methods.

- Haqua Common Gulping Method (HCGM) is one of the various modalities of the Therapeutic Methods of Haqua Gulping (TMHG), depending on schedule tailored to suit the beneficiary, the water temperature and program.

- Hydration is a very different idea scientifically than 'Haquation". Hydrating means making the body absorbing water or another liquid. The term 'Haquate' was coined for this therapy, where the body absorbs water, oxygen, hydrogen, and energy.

- The regular method for testing the temperature of Haqua is recommended by being able to fill up your mouth at one gulp without burning.

- We recommend using a thermometer to check the temperature of the Haqua. So long as it does not burn the mouth, however, it is important to keep the Haqua at a high temperature.

- It is important that the maximum temperature of the Haqua is maintained at $50^{\circ} \mathrm{C}\left(122^{\circ} \mathrm{F}\right)$ and the availability of hydrogen, oxygen, and energy is high.

- Boiled water can be mixed with warm or cold water to reach the desired temperature as recommended.

- Water can be heated up by any method available to you: water heater, water dispenser, microwave, wood, electric boiler, gas for heating, etc.

- It is strongly recommended that the entire quantity of Haqua is taken in a time frame of 1-2 minutes, except in instances where the temperature is too high for rapid gulping.

- For those who wish to use Therapeutic Methods of Haqua Gulping (TMHG) at home, we recommend using a transparent glass mug to allow the essential connection between the human consciousness and the water.

\section{Part 03- Haqua compress therapy (HCT)}

Haqua Compress Therapy (HCT), or simply the Compress Method (CM), should only be performed by a professional Holistic Health Therapist or a certified Massage Therapist to prevent injury.

Section 01- Therapeutic methods for personal or home USE

\section{Option I (recommended)}

- Boil water in a wireless water boiler and place it in a safe area near your shower.

- $\quad$ Take a hot shower and thoroughly clean your body.

- After showering, pour Haqua from the shower tap into a container or basin, filling only $3 / 4$ of the container.

- Add boiled water from the water boiler to the container or basin.

- Immerse a small towel (approximately $30 \mathrm{~cm} x 30 \mathrm{~cm} / 1 \mathrm{ftx} 1 \mathrm{ft}$ in size) halfway or fully in the basin filled with Haqua. Maintain a temperature of around $70^{\circ} \mathrm{C}-80^{\circ} \mathrm{C} / 160^{\circ} \mathrm{F}-180^{\circ} \mathrm{F}$ in the basin.

- $\quad$ Test the temperature of the wet towel with your hand. Make sure that it is not too hot.

- Gently rub and massage all parts of your body, following the Therapeutic Steps below. Each part should be done once or twice. After each step, re-wet your towel. This will maintain a steady heat throughout the process.

- The overall process should take around four minutes.

- It is recommended to use this therapy once daily, four to five days per week.

- $\quad$ Two towels will be needed.

Therapeutic steps: Towel 1

- Face.

- Neck

- Right shoulder, covering the front and back parts of your shoulder.

- Left shoulder, covering the front and back parts of your shoulder.

- $\quad$ Right hand up to the fingers.

- Left hand up to the fingers.

- Chest down to the stomach.

- $\quad$ Right leg down to the ankle.

- $\quad$ Left leg down to the ankle.

- Right foot, covering the tops and bottoms of the foot and toes.

- $\quad$ Left foot, covering the tops and bottoms of the foot and toes. 
Therapeutic steps: Towel 2

- Apply to the genital part of your body.

Section 02- Health benefits in relation to Parkinson's disease

- Stimulates blood circulation.

- Rejuvenates the body.

- Heat penetration also increases the body's energy.

- Increases blood flow, allowing the proper flow of liquids, oxygen, hydrogen, and energy to the brain.

Part 04- Haqua diet therapy (HDT)

- Getting a comprehensive, healthy lifestyle starts with a proper diet, moderate exercise, and Haqua Revitalize ${ }^{\circledR}$ Therapy (HART).

- $\quad$ There are many side effects associated with preservatives in food, yet fresh, preservative-free food is hard to locate promptly. Haqua Revitalize ${ }^{\circledR}$ Therapy (HART)aids both in general and specific health and eliminates the toxic substances accumulated in the body due to the food we eat. Having this therapy can transform our lives and the lives of our future generations, and we will be in better health and well-being for a long time to come.

- Haqua Diet Therapy (HDT) reduces daily food intake by 50$70 \%$. This practice allows the body to absorb natural, clean energy by 'Haquation'.

- As the human body obtains most of its energy from the food consumed daily, eating less can cause the metabolic rate to be lowered due to the body's effort to conserve energy. Although this new diet therapy has a scientific rationale, it also solves the previously mentioned problem. Through the process of 'Haquation,' Haqua provides energy to the body, reducing food metabolism's role in energy production.

- As a result, the amount of food eaten daily should be lowered when using the Therapeutic Methods of Haqua Gulping (TMHG) and Haqua Diet Therapy (HDT).

\section{Section 01- Methodology}

Using Haqua Diet Therapy (HDT), the method of implementing Therapeutic Methods of Haqua Gulping Therapies (TMHG) daily can be implemented at specific temperatures for adults and children.

\section{Section 02- Substituting food with haqua}

- Don't consume diet foods that have been extracted from their protein and minerals.
- You should limit the consumption of fast food to once or twice a week.

- $\quad$ Foods that are fried should be avoided. You can steam some fried foods before eating them in exceptional circumstances when you can only eat fried food. If you steam them, you will reduce the amount of oil on the food. If you grill them, you can reduce the amount of oil on the food as well.

- $\quad$ Every three hours eat a small amount of healthy dry food. Your appetite will be suppressed.

- Make sure you hydrate your body through the gulping method 15-30 minutes before meals (by consuming a glass of Haqua).

- Do not leave your body without being 'Haquated' for more than three hours.

- You should not gulp down more than one liter (34 ounces) or two glasses of $500 \mathrm{ml}$ (17 ounces) of Haqua in one sitting, or within an hour.

- A heavy meal should not be eaten more than twice a week.

- Whenever you are hungry, consuming a very small amount of food is healthier. No set time should be followed.

- Have your daily favorite drink such as coffee, tea, or warm fresh juice every day. Avoid very cold drinks as much as possible.

- Ensure you are getting the nutrition you need from what you eat. You should be able to satisfy your body's vitamin and protein needs with just a small portion of fresh fruits, green vegetables, meat, poultry, and fish.

- $\quad$ Take a twenty-minute walk every day as part of your regular exercise routine. A moderate daily exercise routine is preferable to a vigorous one.

\section{Section 03- Therapeutic benefits}

- Minimizing metabolic wastes as a result of metabolism

- It is possible to improve the enzymes to break down more calories without any physical activity.

- Involve Haqua for most of the energy obtained, rather than from food.

- A reduction of $50-70 \%$ and even as much as $90 \%$ is possible by reducing the daily food volume. Therefore, toxic substances from food metabolism are dramatically reduced, including carbon dioxide $\left(\mathrm{CO}_{2}\right)$, methane $\left(\mathrm{CH}_{4}\right)$, nitrogen compounds $(\mathrm{N})$, phosphates, and hydrogen sulfide $\left(\mathrm{H}_{2} \mathrm{~S}\right)$.

- $\quad$ The energy for the cells is effortlessly provided by Haqua Revitalize ${ }^{\circledR}$ Therapy (HART), reducing the need for enzymes.

- $\quad$ Supplies the body with its natural fuels, the FEELs. 
- Acts as a natural and effortless way to lose weight.

- Helps prevent diseases associated with obesity, such as kidney diseases and artery diseases, hypertension, and cardiovascular diseases.

- Maintains a steady temperature in the body, which encourages healthy bodily functions.

- Increases bone density for underweight individuals, thus increasing body weight.

- Replaces food-based energy with cleaner sources of energy

- Improving productivity and concentration accuracy, getting rid of obesity, building a slim body, etc. Reduce the likelihood of diseases and other health conditions, mood swings, and depression.

- Increases physical activity levels unprecedentedly.

- Bolsters the immune system in its ability to fight viruses, bacteria, fungi, and toxins, reduces wrinkles, and increases physical activity.

- Enhances the balance between human needs for food and food production, thus reducing poverty.

- As this new global food system changes and saves human lives, it contributes to ending wars, conflicts, and fighting without any success.

\section{Results/Anecdotal evidence}

An Arab female's Parkinson's Disease improved by 70\% with Haquapathy

- F.Ab- Unfortunately, I did not know the live broadcast, I would have reacted. I left the medication.

- $\quad$ F.Ab- Thank you very much, and may God bless you. I started the treatment with hot water and I am getting better. I am sick with Parkinson's, but I want how to adhere to the diet. Eating Please answer me and reward you with God.

- $\quad$ F.Ab- I testify before God and with the power of God firstly that everything this man says is true, God willing, because I have tested it, and I stopped my medication completely, by the permission of the Merciful, and I thank God and then this doctor, may God reward him with good for us.

- Khadijah Alghamdi- My sister, what disease do you have ???

- $\quad$ F. Ab- @Hadija_ghamdi- I have Parkinson's disease

- $\quad$ F. Ab-And I see in me, thanks to God, say seventy percent, the symptoms have gone [34].

An Arab female's Parkinson's Disease improved with Haquapathy
- $\quad$ Games with is- May the peace, mercy and blessings of God be upon you. May God bless you, Doctor. I am sick of Parkinson's Disease. Good news for my Parkinson's disease. Hot water is very, because I tried it, and I am on my way to get cure.

- $\quad$ Lahssan Compte- Peace be upon you, may God heal you as I tell you. People drink warm water. This is wrong. They did not use hot water. This is the secret and peace.

- Molay Jalloul- Kindly, how long did it take you on this therapy?

- Lahssan Compte- Peace be upon you. I started treatment with water on 9/16/2020. Praise be to God my brother. I thank Doctor God preserves you and prolongs your life. Finally, my brother, drink hot water at a degree of 50 degrees. This is the secret of this medicine and you apply patience until you recover and peace

- $\quad \tilde{A}$ ãæmø-Peace, my dear sister, please respond. I am sick with Parkinson's. I want to know how I used hot water. I am in critical condition, very sick, and I need this experience [35].

\section{Conclusion}

So, we concluded that, the issue of diet has been the subject of several scientific debates and controversies. A variety of scientific studies have been conducted to prove the effectiveness of a specific recommended diet. Still, the results of these studies have led to various controversies, with time passing, due to several factors.

Natural fuels are essential to the human body. FEELs stand for Four Essential Elements of Life. The body's essential fuels, which we investigated extensively over the past fourteen years, could be the ultimate solution to resolve the various controversies surrounding diet. It has been found that they are crucial for metabolizing your food so that your body can produce energy to breathe, circulate blood, build muscles, grow and repair cells and do all the other things it does to survive. The excretion of the toxic substances produced by metabolism is also dependent upon these fuels. You should minimize the amount of food you eat and replace it with Haqua, allowing the body to rely on Haqua for the energy it needs, which would be safer than relying on the food you eat.

\section{Bibliography}

1. "What Is Parkinson's?" The Parkinson's Foundation (2020).

2. "What is Parkinson's Disease?" American Parkinson Disease Association (2020).

3. “Causes of Parkinson's". American Parkinson Disease Association (2020). 
4. "Drug-induced tremor". MedlinePlus. U.S. National Library of Medicine (2021).

5. “What Causes Drug-Induced Parkinsonism?" Healthline Media. Medically reviewed by Alyssa Peckham, PharmD, BCPP Written by Corey Whelan on June 21, 2021 (2021).

6. "Drug-induced parkinsonism". American Parkinson Disease Association. Posted on September 29, 2020 by Dr. Rebecca Gilbert (2021).

7. “Kaldas Center for Fertility, Surgery and Pregnancy, SC” (2016).

8. "The Fetal Life-Support System: Placenta, Umbilical Cord, and Amniotic Sac". American Pregnancy Association (2016).

9. Patrick Flanagan MD. "Hydrogen... Longevity's Missing Link". (2021).

10. Heather aKropp and Angela Halasey. "The Recipe for Plant Growth. ASU - Ask A Biologist” (2015).

11. "The hydrologic cycle". National Oceanic and Atmospheric Administration (2019).

12. "Heat Energy - Definition and Examples". about education. (2012).

13. "Metabolism and weight loss: How you burn calories" (2019).

14. Szent-Gyorgyi A. "Metabolism and cancer". International Journal of Quantum Chemistry 28 (1985): 257-261.

15. "Dancing with water. Hydrogen: Fuel of Life" (2016).

16. Hartman Carl and Bibb Lewis. "The Human body and its enemies: a textbook of physiology hygiene and sanitation". World Book Co., (1913): 232.

17. “Heat Transfer". Wikipedia the Free Encyclopedia (2016).

18. “Water for Health". Pure Water Services (2018).

19. "Science Dictionary" (2012).

20. "Heat transfer". Wikipedia the free encyclopedia (2012).

21. "Temperature Dependence of the pH of pure Water" (2017).

22. "Rural Well Water Linked to Parkinson's Disease". Marla Cone. August 5, 2009. Scientific American.

23. Ueki A and Otsuka M. "Life style risks of Parkinson's disease: association between decreased water intake and constipation". Journal of Neurology 251 (2004): vII18-vII23.
24. Adler L. "Dehydration in Parkinson's: Symptoms, Risks and Tips" (2017).

25. Sun HL., et al. "Plasma $\alpha$-synuclein levels are increased in patients with obstructive sleep apnea syndrome". Annals of Clinical and Translational Neurology 6.4 (2019): 788-794.

26. “How Does Temperature Affect pH?" Westlab.com (2021).

27. Brenner S. "Parkinson's disease may be due to failure of melanin in the Substantia Nigra to produce molecular hydrogen from dissociation of water, to protect the brain from oxidative stress". Medical Hypotheses 82.4 (2014): 503.

28. Yoshii Y., et al. "Complexity of Stomach-Brain Interaction Induced by Molecular Hydrogen in Parkinson's Disease Model Mice". Neurochemical Research 42.9 (2017): 2658-2665.

29. Fujita K., et al. "Hydrogen in drinking water reduces dopaminergic neuronal loss in the 1-methyl-4-phenyl-1,2,3,6-tetrahydropyridine mouse model of Parkinson's disease". PLoS One 4.9 (2009): e7247.

30. "Fatigue in parkinson's disease". American Parkinson Disease Association (2020).

31. "Boil Water Response - Information for the Public Health Professional". Department of Health. New York State (2018).

32. “Boiling”. Wikipedia. The Free Encyclopedia (2012).

33. “Boil Water". WHO (2021).

34. https://youtu.be/a7UT3XHRQE4

35. https://youtu.be/NqLxiQfWRIM

\section{Assets from publication with us}

- Prompt Acknowledgement after receiving the article

- Thorough Double blinded peer review

- Rapid Publication

- Issue of Publication Certificate

- High visibility of your Published work

Website: www.actascientific.com/

Submit Article: www.actascientific.com/submission.php Email us: editor@actascientific.com

Contact us: +919182824667 